\title{
Effect of Empowering Education on Refined Nursing of Patients with Internal Double J Tubes after Surgery for Ureteral Stricture
}

\author{
Shasha Li, Guili Cheng, Huihong Huang, Wenjuan Ren \\ The Third Affiliated Hospital of Zhongshan University, Guangzhou, China \\ Email: 121885369@qq.com
}

How to cite this paper: Li, S.S., Cheng, G.L., Huang, H.H. and Ren, W.J. (2021) Effect of Empowering Education on Refined Nursing of Patients with Internal Double J Tubes after Surgery for Ureteral Stricture. Open Journal of Nursing, 11, 291301.

https://doi.org/10.4236/ojn.2021.115026

Received: March 26, 2021

Accepted: May 15, 2021

Published: May 18, 2021

Copyright $\odot 2021$ by author(s) and Scientific Research Publishing Inc. This work is licensed under the Creative Commons Attribution International License (CC BY 4.0).

http://creativecommons.org/licenses/by/4.0/

\begin{abstract}
Objective: To investigate the effect of the theory of enabling education on the fine management of patients with internal double $J$ tubes after ureteral stricture. Methods: Eighty patients with built-in double J tubes after ureteral stricture were selected from the urology department of a grade a hospital in Guangzhou. The patients were divided into control group and observation group by random number method, with 40 patients in each group. The control group received refined nursing after surgery, while the observation group received refined nursing including the theory of empowerment education after surgery on the basis of the control group. Results: After the intervention, the observation group had a higher standard rate of quality indicators, higher self-efficacy score than the control group $(\mathrm{P} \leq 0.05)$, lower scores of ureteral stent-related symptoms, urinary system symptoms, pain symptoms, total health status, job performance, additional problems and total scores than the control group $(P \leq 0.05)$, and statistically significant differences were found in the total health status dimension and total scores $(P \leq 0.01)$. The nursing satisfaction survey, the scores of clinical nursing, health education, psychological counseling and nurse-patient communication were all higher than those in the control group $(\mathrm{P} \leq 0.05)$, and the differences in health education and nurse-patient communication were statistically significant $(\mathrm{P} \leq 0.01)$. Conclusion: The theory of enabling education can improve patients' self-nursing level, promote the implementation of refined nursing quantitative indicators and nursing measures, relieve the poor symptoms of ureteral stricture patients, and improve patients' satisfaction with nursing work.
\end{abstract}

\section{Keywords}

Empowering Education, Double J Tube, Refined Care 


\section{Introduction}

With the continuous understanding and advancement of nursing quality, clinical nursing work is more inclined to carry out precise and detailed management for nursing intractable problems. Based on the "people-oriented" nursing concept, more detailed and precise nursing measures and health education are implemented to improve the quality and level of nursing [1]. Empowering education theory can enable patients to assume the responsibility of self-management of health, improve patients' ability of self-care, play a positive role in disease rehabilitation [2] [3], and better promote the implementation of nursing measures and health education. Ureteral stenosis can be divided into primary and secondary, often causing hydronephrosis, urinary calculi and repeated urinary tract infections in patients, seriously leading to renal failure. Ureteral stricture balloon expansion recent success rate as high as $18 \%$ to $83 \%$ in the treatment of ureteral stenosis [4]. This technique is relatively simple to operate and widely used in clinical practice, but double J tubes (ureteral stent tubes) need to be placed for 6 weeks to 3 months or even longer after surgery to support the stenosis segment and assist drainage of urine to reduce the burden of the kidney [5] [6] [7] [8]. The discomfort caused by the long-term indwelling of double J tubes is multifacet, including symptoms of urine storage, bladder irritation, back pain and hematuria, and some of them may cause erectile dysfunction in male patients [9] [10] [11], which has an impact on the body and mind of patients. Literature shows that there are few reports on the application of the theory of empowering education and refined nursing in patients with urinary stricture after surgery. In order to promote postoperative rehabilitation of patients, implement refined nursing and improve patients' self-care ability, which is different from the previous health education mode, this study applied the combination of empowering education and refined nursing in the rehabilitation management of patients with built-in double J tubes after the surgery of ureteral stricture. Good results have been achieved, and the adverse experience of patients with built-in double J tubes has been reduced. The report is as follows.

\section{Research Objects}

A total of 80 patients with ureteral stenosis who were admitted to the Department of Urology in a third-grade grade a hospital in Guangzhou from February 2020 to January 2021 were selected. During hospitalization, the patients underwent ureteroscopic balloon dilation surgery for ureteral stenosis and double J tubes were indwailed during the operation.

Inclusion criteria:

* patients with clinical diagnosis consistent with the diagnosis of ureteral stensis;

* patients aged 18 - 65 years;

* patients with clear consciousness, normal language expression and comprehension;

* intraoperative double $\mathrm{J}$ tubes of the same material (78XXX/Bed-USA) with 
indwelling time $\geq 2$ months;

* Volunteered to participate in the study and signed the informed consent.

Exclusion criteria:

* patients with other severe cardio-cerebrovascular, lung, liver and other diseases or complications;

* patients with severe renal insufficiency due to various reasons;

* patients with open surgery or post-percutaneous nephrolithotomy stent implantation;

* patients with chronic cystitis or glandular cystitis.

Data of control group and observation group: control group, age 19 - 65 (41.45 \pm 4.04 ) years old; gender, male 22 cases, female 18 cases; marital status, married 28 cases, unmarried 10 cases, divorced/widowed 2 cases; educational level: college or above in 26 cases, middle school in 8 cases, primary school in 6 cases; the ureteral stenosis was found in 22 cases on the left side, 16 cases on the right side, and 2 cases on both sides. Observation group, aged 18 - 64 (43.45 \pm 3.20$)$ years; gender, male 23 cases, female 17 cases; marital status: 27 cases were married, 12 cases were unmarried, and 1 case was divorced/widowed. Education level: college or above 25 cases, middle school 10 cases, primary school 5 cases; the ureteral stenosis was found in 25 cases on the left side, 12 cases on the right side and 3 cases on both sides. There was no statistical difference $(P \geq 0.05)$ between the two groups in general data.

\section{Research Methods}

Control group implemented precise and detailed management nursing and on the basis of the control group, the patients of the observation group received postoperative nursing care incorporating the theory of empowering education.

\subsection{Control Group}

Implemented precise and detailed management nursing, graded the nursing process and set up refined target management. The first-level refinement includes daily observation, intervention, propaganda and education, and distribution of health education manuals in terms of drinking water implementation rate, awareness rate of postoperative correct activities, pain management implementation rate, self-monitoring accuracy rate, etc. The second-level refinement includes analyzing and solving the problems in the first-level refinement objective management. The head of quality control management timing carries out quality control by the evaluation indicators. Continuing care to patients was given at 1 week, 3 weeks and 6 weeks after discharge through telephone follow-up.

\subsection{Observation Group}

Establish an enabling educational nursing team, consisting of the nurse leader (initiator and quality controller), 2 specialist nurses (training instructor and attendant), 5 primary nurses (educator and respondent) and 1 clinician (specialist consultant). Review relevant literature to develop an empowering education 
program, including problem discovery, emotional communication, goal setting, plan determination, behavior evaluation, communication skills training, content and methods of visits. Assess these contents to see how well the members have mastered them, finally. Then implementation of the empowering education program:

\subsubsection{Problem Discovery}

Visiting plan was developed based on the principle of management by objectives. Postoperative patients were interviewed using semi-structured interview method: "How do you feel now?" "Did you know you had double J tubes in your body?" "Do you know the requirements for drinking water after surgery?" "What is the biggest problem for you if you are discharged with a tube?" We can know the largest existing problems of the patients, their awareness of the disease and indwelling double J tubes, and their demand for postoperative rehabilitation through discussion and inquiry. Because the double J tubes needs to be indwelling in the body for a period of time, home care is very important for the patient's postoperative recovery. We can emphasize the important role of patients in postoperative rehabilitation, especially in home care, and understand the attitude of patients towards self-care.

\subsubsection{Emotional Communication}

Through patient listening and empathy, we can encourage the patients to talk about the troubles caused by the indwelling catheter, and give the emotional support to gain the patient's trust. In addition, the patients' living environment, living habits, physical conditions and other factors are further understood in the communication. We decompose these contents including the patient's own situation, the cause of disease, characteristics, necessity of indwelling double J tubes and common problems into multiple knowledge points and integrate them into emotional communication with patients, so that patients can stimulate their consciousness of self-management by autocriticism, then establisht their self-goals.

\subsubsection{Goal Setting}

Encourage patients to set goals for improvement of their own problems, follow-up nurses supplement. Sure the patient's positive attitude first, and then combined with the patient's own habits, to use professional knowledge gives corresponding suggestions, guide the patients to refine these goals which are close to their lives and easy to implement. For example: "I think it's really great that you think that way." "What do you think is the easiest thing to do about drinking water?" And will leave the final decision to the patient, improve the patient's initiative and compliance.

\subsubsection{Determine the Plan}

Guide patients to develop a self-rehabilitation plan according to the target, including drinking water, activities, pain, self-management and other aspects, pay attention to family support, avoid excessive cumbersome measures. We should know the situation of the implementation and problems of the plan at any time, 
and give targeted guidance to correct the deviation in time to ensure the effectiveness of the implementation of the plan; at the same time, patients can realize their attention and increase their confidence in the implementation of the plan. For example, drinking water plan: help patients to set a tolerated amount of drinking water, let patients choose to use a calibrated drinking cup, use mobile phone timing or post-it note reminder function, use urine colorimetric card to self-monitor urine color and realize the amount of drinking water, and encourage family members to participate in supervision.

\subsubsection{Behavioral Evaluation}

Empowerment teams do periodic evaluations, often by asking, "How is your water plan going?" "Is the discomfort in your waist alleviating?" "Do you feel there is anything you need to change in your recovery plan?" To understand the implementation of patients' plans and patients' attitude to plans, to encourage and support patients' goals, to answer and make suggestions for patients' doubts and problems, to establish new goals when necessary, to help patients complete the rehabilitation plan, and to integrate health promotion measures into their daily life in the future.

\section{Evaluation Methods and Observation Indicators}

\subsection{Data Collection}

Nursing quality indicator, the self-efficacy scale, the questionnaire of ureteral stent-related symptoms was collected and compared by checking list and questionnaire issued by follow-up nurses before and after intervention. Nursing satisfaction questionnaire was distributed by the responsible nurse after intervention.

\subsection{Indicators of Observation}

* The standard rate of specialized nursing quality indicators. The department formulated relevant nursing quality indicators to evaluate patients with indwelling double J tubes: drinking water implementation rate, awareness rate of postoperative activities, self-monitoring accuracy rate.

* The general self-efficacy scale (GSES) was used to assess patients' conscious ability to adopt adaptive behaviors in disease. The scale was compiled by Schwarz in 1981, and the Chinese version was translated and revised by Wang Caikang [12] in 2001. It includes 10 items and adopts the Likert 4-point scale model, with each item scoring $1-4$ points. The higher the score, the higher the patient's confidence in self-management. The Cronbach's $\alpha$ coefficient of the scale is 0.87 , the retest reliability is 0.83 , and the halving reliability is 0.90 .

* The Ureteral Stent Symptoms Questionnaire (USSQ) was used to evaluate the symptoms of patients with indwelling ureteral stents. The scale in 2003, Joshi is equal to 2003 years of development, Chinese version translated by Tian Meng Zhen [13] in 2020, the questionnaire of Cronbach's alpha coefficient is 0.923 , the general questionnaire scores between $26-170$ points, the field of urinary symptoms score between 9 and 55 points, pain score between 
0 - 31 points, general state of health score between 6 and 30 points, performance related entry score between 3 to 15 points, sex related score between 3 to 12 points, The score of additional questions ranged from 5 to 27 points. The higher the score, the more severe the clinical symptoms, the worse the overall health status, and the worse the satisfaction and perception of the stent.

* The hospital self-made nursing satisfaction questionnaire, including clinical nursing, humanistic care, health education, nursing and patient communication 4 factors, a total of 17 items. Items were scored according to the Likert rating method of the standard satisfaction questionnaire, with the options as extremely poor, dissatisfied, average, relatively satisfied, and very satisfied. The corresponding points were 1 to 5 points. The higher the score, the more satisfied the patient was with the care.

\subsection{Statistical Methods}

SPSS 17.0 statistical software was used for analysis. Enumeration data were expressed by frequency and rate (\%), and $\chi^{2}$ test was used for comparison between groups. Measurement data were expressed as mean \pm standard deviation ( $\mathrm{x} \pm \mathrm{s}$ ), and $t$ test was used for comparison between groups. $\mathrm{P}<0.05$ was considered statistically significant.

\section{The Results}

There was no significant difference between the two groups in the rate of specialized quality indicators before intervention, but there was significant difference after intervention ('Table 1).

Table 1. Comparison of the compliance rate of specialty quality indicators between the two groups before and after intervention (\%).

\begin{tabular}{|c|c|c|c|c|c|c|c|}
\hline \multirow[t]{2}{*}{ Group } & \multirow[t]{2}{*}{ Number } & \multicolumn{2}{|c|}{ Drinking water implementation rate } & \multicolumn{2}{|c|}{$\begin{array}{c}\text { Awareness rate of postoperative } \\
\text { activities }\end{array}$} & \multicolumn{2}{|c|}{ Self-monitoring rate } \\
\hline & & pre-intervention & post-intervention & pre-intervention & post-intervention & pre-intervention & post-intervention \\
\hline Control group & 40 & $14(35.0)$ & $31(77.5)$ & $16(40.0)$ & $32(80.0)$ & $10(25.0)$ & $30(75.0)$ \\
\hline Observation group & 40 & $12(30.0)$ & $38(95.0)$ & $18(45.0)$ & $38(95.0)$ & $12(30.0)$ & $39(97.5)$ \\
\hline $\mathrm{X}^{2}$ & & 0.228 & 5.165 & 0.205 & 4.114 & 0.251 & 8.538 \\
\hline $\mathrm{P}$ & & $>0.05$ & $<0.05$ & $>0.05$ & $<0.05$ & $<0.05$ & $<0.05$ \\
\hline
\end{tabular}

There was no significant difference between the two groups in the self-efficacy scores before intervention, but there was significant difference after intervention (Table 2).

Table 2. Comparison of general self-efficacy scores between the two groups before and after intervention (points, $\mathrm{x} \pm \mathrm{s}$ ).

\begin{tabular}{cccc}
\hline \multirow{2}{*}{ Group } & \multirow{2}{*}{ Number } & \multicolumn{2}{c}{ General self-efficacy scores } \\
\cline { 3 - 4 } & & pre-intervention & post-intervention \\
\hline Control group & 40 & $23.15 \pm 4.04$ & $26.45 \pm 4.21$ \\
\hline
\end{tabular}




\section{Continued}

\begin{tabular}{|c|c|c|c|}
\hline Observation group & 40 & $23.00 \pm 3.68$ & $29.85 \pm 3.24$ \\
\hline $\mathrm{t}$ & & -0.123 & -2.859 \\
\hline P & & 0.379 & 0.007 \\
\hline
\end{tabular}

The urinary symptoms, pain symptoms, total health status, job performance, additional problems and total scores of patients in the two groups during catheterization after intervention were statistically significant compared with those before intervention (Table 3). And the comparison between two groups of patients after intervention, scores of other dimensions except sexual life dimension in the observation group were lower than those in the control group (Table 4).

Table 3. Internal comparison of various dimensions and overall scores of ureteral stent-related symptoms in each group before and after intervention (points, $\mathrm{x} \pm \mathrm{s}$ ).

\begin{tabular}{|c|c|c|c|c|c|c|c|c|c|c|c|}
\hline \multirow[b]{2}{*}{ Group } & \multirow[b]{2}{*}{ Number } & \multicolumn{2}{|c|}{ Urinary symptoms } & \multicolumn{2}{|c|}{ Body pain } & \multicolumn{3}{|c|}{ General health } & \multicolumn{3}{|c|}{ Work performance } \\
\hline & & Control group & $\begin{array}{l}\text { Observation } \\
\text { group }\end{array}$ & Control group & $\begin{array}{l}\text { Observation } \\
\text { group }\end{array}$ & Control group & \multicolumn{2}{|c|}{$\begin{array}{l}\text { Observation } \\
\text { group }\end{array}$} & \multicolumn{2}{|c|}{ Control group } & $\begin{array}{c}\text { Observation } \\
\text { group }\end{array}$ \\
\hline pre-intervention & 40 & $34.35 \pm 6.66$ & $32.55 \pm 6.09$ & $20.60 \pm 3.44$ & $20.40 \pm 3.03$ & $19.15 \pm 2.62$ & \multicolumn{2}{|c|}{$18.75 \pm 2.31$} & \multicolumn{2}{|c|}{$9.950 \pm 2.70$} & $10.75 \pm 2.53$ \\
\hline post-intervention & 40 & $30.10 \pm 4.78$ & $26.45 \pm 5.71$ & $17.25 \pm 3.89$ & $14.00 \pm 3.32$ & $16.30 \pm 2.56$ & \multicolumn{2}{|c|}{$12.80 \pm 2.39$} & \multicolumn{2}{|c|}{$7.800 \pm 1.98$} & $6.350 \pm 2.0$ \\
\hline $\mathrm{t}$ & & 2.317 & 3.266 & 2.884 & 6.360 & 3.481 & \multicolumn{2}{|c|}{-7.986} & \multicolumn{2}{|c|}{2.864} & -6.091 \\
\hline $\mathrm{P}$ & & 0.026 & 0.02 & 0.006 & $<0.001$ & 0.001 & \multicolumn{2}{|c|}{$<0.001$} & \multicolumn{2}{|c|}{0.007} & $<0.001$ \\
\hline \multirow{2}{*}{ Group } & \multirow{2}{*}{ Number } & \multicolumn{3}{|c|}{ Sexual matters } & \multicolumn{3}{|c|}{ Addition problems } & \multicolumn{4}{|c|}{ Overal scorses } \\
\hline & & Control group & \multicolumn{2}{|c|}{ Observation group } & Control group & \multicolumn{2}{|c|}{ Observation group } & \multicolumn{2}{|c|}{ Control group } & \multicolumn{2}{|c|}{ Observation group } \\
\hline post-intervention & 40 & $4.850 \pm 4.36$ & 4.150 & \pm 3.82 & $3.150 \pm 2.94$ & $10.750 \pm 1.8$ & & 89.450 & \pm 10.19 & & $.500 \pm 7.486$ \\
\hline $\mathrm{t}$ & & 0.804 & -1 & .551 & 2.447 & -4.424 & & & 584 & & -10.222 \\
\hline $\mathrm{P}$ & & 0.426 & & 129 & 0.019 & $<0.001$ & & & .001 & & $<0.001$ \\
\hline
\end{tabular}

Table 4. Comparison of different dimensions and overall scores of ureteral stent-related symptoms between the two groups before and after intervention (points, $\mathrm{x} \pm \mathrm{s}$ ).

\begin{tabular}{|c|c|c|c|c|c|c|c|c|c|}
\hline \multirow[b]{2}{*}{ Group } & \multirow[b]{2}{*}{ Number } & \multicolumn{2}{|c|}{ Urinary symptoms } & \multicolumn{2}{|c|}{ Body pain } & \multicolumn{2}{|c|}{ General health } & \multicolumn{2}{|c|}{ Work performance } \\
\hline & & $\begin{array}{c}\text { pre- } \\
\text { intervention }\end{array}$ & $\begin{array}{c}\text { post- } \\
\text { intervention }\end{array}$ & $\begin{array}{c}\text { pre- } \\
\text { intervention }\end{array}$ & $\begin{array}{l}\text { post- } \\
\text { intervention }\end{array}$ & $\begin{array}{c}\text { pre- } \\
\text { intervention }\end{array}$ & $\begin{array}{c}\text { post- } \\
\text { intervention }\end{array}$ & $\begin{array}{c}\text { pre- } \\
\text { intervention }\end{array}$ & $\begin{array}{l}\text { post- } \\
\text { intervention }\end{array}$ \\
\hline Control group & 40 & $34.35 \pm 6.66$ & $30.10 \pm 4.78$ & $20.60 \pm 3.44$ & $17.25 \pm 3.44$ & $19.15 \pm 2.62$ & $16.30 \pm 2.56$ & $9.950 \pm 2.70$ & $7.800 \pm 1.98$ \\
\hline Observation group & 40 & $32.55 \pm 6.09$ & $26.45 \pm 5.71$ & $20.40 \pm 3.03$ & $14.00 \pm 3.32$ & $18.75 \pm 2.31$ & $12.80 \pm 2.39$ & $10.75 \pm 2.53$ & $6.350 \pm 2.01$ \\
\hline $\mathrm{t}$ & & 0.891 & 2.191 & 0.195 & 2.840 & 0.512 & -4.466 & -0.966 & -2.295 \\
\hline $\mathrm{P}$ & & 0.378 & 0.035 & 0.846 & 0.007 & 0.612 & $<0.001$ & 0.340 & 0.027 \\
\hline \multirow{2}{*}{ Group } & \multirow{2}{*}{ Number } & \multicolumn{3}{|c|}{ Sexual matters } & \multicolumn{2}{|c|}{ Addition problems } & \multicolumn{3}{|c|}{ Overal scorses } \\
\hline & & pre-interven & tion post-inte & ervention pre & -intervention & post-interven & ntion pre-inte & rvention pos & st-intervention \\
\hline Control group & 40 & $6.050 \pm 5$. & 4.850 & \pm 4.36 & $6.100 \pm 4.51$ & $13.150 \pm 2$ & 105.300 & \pm 11.62 & $9.450 \pm 10.19$ \\
\hline
\end{tabular}




\section{Continued}

\begin{tabular}{cccccccc}
\hline Observation group & 40 & $6.250 \pm 4.68$ & $4.150 \pm 3.82$ & $15.300 \pm 4.20$ & $10.750 \pm 1.86$ & $104.000 \pm 10.51$ & $74.500 \pm 7.486$ \\
$\mathrm{t}$ & -0.130 & -0.539 & 0.580 & -3.083 & 0.371 & -5.286 \\
$\mathrm{P}$ & 0.897 & 0.593 & 0.566 & 0.004 & 0.713 & $<0.001$ \\
\hline
\end{tabular}

The patients' satisfaction scores of the observation group was significantly higher than that of the control group (Table 5).

Table 5. Comparison of nursing satisfaction scores after intervention between the two groups (points, $\mathrm{x} \pm \mathrm{s}$ ).

\begin{tabular}{cccccc}
\hline Group & Number Clinical nursing & $\begin{array}{c}\text { Health } \\
\text { education }\end{array}$ & $\begin{array}{c}\text { Psychological } \\
\text { counseling, }\end{array}$ & $\begin{array}{c}\text { Nursing and patient } \\
\text { communication }\end{array}$ \\
\hline Control group & 40 & $17.00 \pm 1.41$ & $25.65 \pm 1.95$ & $16.65 \pm 1.89$ & $12.45 \pm 1.09$ \\
Observation group & 40 & $18.15 \pm 1.81$ & $28.10 \pm 1.71$ & $18.05 \pm 1.63$ & $13.85 \pm 1.13$ \\
$\mathrm{t}$ & & -2.236 & -4.216 & -2.479 & -3.960 \\
$\mathrm{P}$ & 0.032 & $<0.001$ & 0.017 & $<0.001$ \\
\hline
\end{tabular}

\section{Discussion}

1) Under the empowering education theory, fine nursing can improve the self-care level of patient with built-in double $J$ tubes after surgery for ureteral stricture, and promote the implementation of nursing quantitative indicators and nursing measures. double J tubes destroyed the ureteral wall within the period of the normal physiological function, as a foreign object, activity is easy to damage caused by ureteral mucosa bleeding, pass urine bladder pressure increased, leading to reflux, bad habits and easy cause urinary tract infection and stone [14] [15] [16], so there are more certain requirements for the postoperative patients with drinking water, activities, self-observation of urination and body pain. Refined nursing can quantify these contents and monitor the results, which is beneficial to nursing effect evaluation and clinical quality improvement. The results of this study showed that the improvement of self-efficacy under the empowering concept was more obvious (Table $2, \mathrm{P} \leq 0.05$ ), and the achievement rate of refined nursing indicators was also higher (Table $1, \mathrm{P} \leq 0.05$ ). By guiding patients to participate in their own health planning decisions, the concept of empowerment can stimulate patients' initiative in health management, which can improve individuals' confidence and positive coping style in the face of illness and adversity, namely, the enhancement of self-efficacy. Self-efficacy enhancement can affect individual motivation and determine people's efforts and the persistence of behaviors in realizing behavioral goals [17]. Patients with a higher sense of self-efficacy have a higher level of active efforts, which can effectively ensure the implementation and continuity of measures. In this study, after communication with nurses, patients learned the matters to focus on after catheterization, classified and set goals based on their own environment and needs, 
quantified independent measures to each day (convenient comparison), and selected the way they were accustomed to (convenient implementation) and the monitoring method they understood (convenient evaluation). Due to its strong pertinence, it can find and effectively solve the new problems in the implementation in time, and the relevant indicators reach the standard rate is also higher. The nurse acts as the guide, the encourager and the observer to continuously strengthen the patient's willpower and initiative through communication during the implementation process of the patient's goal.

2) Refined nursing under the concept of enabling can relieve the adverse symptoms of ureteral stricture patients with catheterization, and improve the health status and quality of life of patients during catheterization. Studies [18] [19] show that more than $80 \%$ of patients with catheterization have experienced pain after double $\mathrm{J}$ catheterization, which affects their daily life. Urinary tract infections were found in $24 \%$ to $34 \%$ of patients; $32 \%$ of the patients had post-catheterization sexual dysfunction; fifty-eight percent of patients showed signs of impaired work ability. These will cause anxiety, tension, and further affect the patient's quality of life. These complications are not only related to the location, length and material of the internal double J tube, but also closely related to whether the patients adopt healthy behaviors, including reasonable fluid intake, diet control and daily activities, improvement of bad living habits (constipation, holding back urine, etc.), good self-testing ability and attitude, etc. Only when patients understand relevant health knowledge, can they establish positive and correct beliefs and attitudes, so as to autonomously form healthy behaviors [20]. In this study, patients' knowledge and needs about stent tubes were satisfied by good communication and empowerment, we can mobilize the patient's initiative, make them to jointly formulate appropriate their own personalized solutions, which objectively strengthened the patient's behavior following the doctor's advice, this correct behavior can reduce adverse symptoms caused by stent tube. In the behavior evaluation, nurses can timely relieve patients' emotions, maintain patients' positive and optimistic stable mentality, and timely mediate intervention for problems that patients can't solve, providing strong backing for the implementation of patient empowerment plan. The results of this study showed that the urinary symptoms, pain symptoms, total health status, job performance, additional problems and total scores of patients in the two groups during catheterization after intervention were statistically significant compared with those before intervention (Table 3, $\mathrm{P} \leq 0.05$ ), indicating that actively guided intervention can reduce the discomfort of patients with internal double J tube.

In the comparison between two groups of patients after intervention, scores of other dimensions except sexual life dimension in the observation group were lower than those in the control group (Table 4, P $\leq 0.05$ ), and there were statistically significant differences in scores of the dimension of total health status and total scores $(\mathrm{P} \leq 0.01)$, which indicated that compared with the control group, 
symptoms related to internal double $J$ tubes in the observation group were relieved more obviously, their self-health status was better, and they were easier to return to work and life. In the score related to sexual life, only $40 \%(32 / 80)$ of the patients filled in it, while $60 \%$ of the patients did not fill in it or thought it had nothing to do with double J tube, resulting in no statistical difference in the results before and after the intervention, which was speculated to be related to patients' psychological tolerance to such problems and differences in national conditions, which was also similar to the research results of Tian Mengzhen [20]. The improvement and countermeasure to this kind of problem need further study.

3) Refined nursing under the concept of enabling can improve patients' satisfaction with nursing work (Table $5 \leq 0.05$ ), and it is more obvious in health education and nursery-patient communication $(\mathrm{P} \leq 0.01)$. This shows that under the empowering education, nursery-patient communication is harmonious, nurses play a more active role in helping patients to establish their own beliefs, patients' sense of trust in nurses is also relatively improved, health education measures can be smoothly implemented in daily life, and various problems after double J tubes implantation can be effectively improved. Nurses actively solve the problems of patients themselves, constantly enrich their own experience, improve the level of health education, and form a positive cycle.

\section{Conclusion}

Enable education plays a positive role in the fine nursing of patients with built-in double $J$ tubes after the operation of ureteral stenosis, especially in the implementation of health education and improvement of patients' self-care level, and at the same time to enhance the communication between nurses and patients and improve the quality of life of patients with postoperative catheterization. It is a nursing education model worthy of promotion. Of course, this study also has some limitations, such as the small number of enrolled patients, the single-center study, and the failure to further promote the study on sexual life quality, etc. In the future, a multi-center, multi-case comparative study on empowering education and a targeted study to improve the problem can be carried out.

\section{Conflicts of Interest}

The authors declare no conflicts of interest regarding the publication of this paper.

\section{References}

[1] Ao, Y.Q., Yuan, C., Zuo, L., et al. (2019) The Application of Perioperative Intensive Nursing in Patients Undergoing Thoracoscopic Surgery. Chinese Journal of Modern Nursing, 25, 633-636.

[2] He, B.Q., Shao, X.Y., Li, M.C. and Lou, L.Y. (2016) The Effect of Empowering Education on the Confidence and Satisfaction of Maternal Breastfeeding. Chinese Journal of Modern Nursing, 22, 4242-4245. 
[3] Guan, H. (2016) Empowering Eduationg and Its Application in Health Education Research. Journal of Nursing Science, 31, 111-113.

[4] Kachrilas, S., Bourdoumis, A., Karaolides, T., Nikitopoulou, S., Papadopoulos, G., Buchholz, N. and Masood, J. (2013) Current Status of Minimally Invasive Endoscopic Management of Water Therapeutic. Therapeutic Advances in Urology, 5, 354-365. https://doi.org/10.1177/1756287213505671

[5] Liu, Y.D., Yuan, J., Li, X., Luo, J.T., Zeng, G.H. and Wu, K.J. (2006) Endourology for the Treatment of Ureteral Stricture. Chinese Journal of Urology, 2006, 608-611.

[6] He, Y.Z., Li, X., Yang, W.Q., Feng, G. and Jiang, X.H. (2017) Treatment of Ureteral stricture by Electrosurgical Incision Combined with Balloon Dilation. Chinese Journal of Endoscophal Urology (Electronic Edition), 11, 113-117.

[7] Arya, M., Mostafid, H., Patel, H.R., et al. (2001) Expansion of Benign Ureteric Stents in Long-Term Management of Benign Ureteric Stratitures. BJU International, 88, 339-342. https://doi.org/10.1046/j.1464-410X.2001.02322.x

[8] Erdogru, T., Kutlu, O., Koksal, T., Danisman, A., Usta, M.F., Kukul, E. and Baykara, (2005) M. Endoscopic Treatment of Ureteric Strictures Using Cold-Knife endoureterterotomy and Wall Stents. Urologia International, 74, 140-146. https://doi.org/10.1159/000083285

[9] Zhang, C.X., Wang, J., Xiao, J. and Ye T. (2020) Clinical Significance of Ureteral stent Placement in Patients with Chronic Ureteral Pain. Journal of Clinical Urology, 35, $471-474+481$.

[10] Rong, W. and Bin, X. (2020) Comparison of Erectile Function and Quality of Life in Young and Middle-Aged Men after Ureteral Holmium Laser Lithotripsy. Chinese Journal of Andrology, 26, 48-53.

[11] Nunzio, C., Roehrborn, C.G., Andersson, K., et al. (2017) Erectile Dysfunction and Lower Urinary Tract Symptoms. European Urology Focus, 3, 352-363. https://doi.org/10.1016/j.euf.2017.11.004

[12] Wang, C.K., Hu, Z.Y. and Liu, Y. (2001) Research on the Reliability and Validity of General Self-Efficacy Scale. Applied Psychology, 2001, 37-40.

[13] Tian, M.Z., Zhou, P., Chen, P., Lai, Q.R. and Zhang, C.P. (2020) Chinese Version of the Questionnaire on Ureteral Stent-Related Symptoms and Its Reliability and Validity Analysis. Chinese Journal of Modern Nursing, 26, 2130-2137.

[14] Liu, J.S. and Hrebinko, R.L. (1998) The Use of 2 Ipsilateral Ureteral Stents for Relief of Ureteral Obstruction from Extrinsic compression. The Journal of Urology, 159, 179-181. https://doi.org/10.1016/S0022-5347(01)64050-3

[15] Wang, F.P., Yin, J.B., Zhang, R.K., Song, X.S., Wu, H.C. and Gao, C.Z. (2003) Complications of Ureteral Stent Placement. Chinese Journal of Surgery, 2003, 77.

[16] Tang, W.Y. and Xia, S.J. (2012) Research Progress of the Effect of Ureteral Stent on Upper Urinary Tract. Clinical Journal of Urology, 27, 711-716.

[17] Jin, Y.H., Shi, S.S. and Cui W.X. (2014) The Influence of Head Nurse Empowerment Behavior on Nurses' Self-Efficacy and Sense of Work Control. Chinese Journal of Nursing, 49, 104-107.

[18] Lu, R.S., Cai, H. and Pan, X.M. (2016) Cause Analysis and Nursing Countermeasure of Common Complications of Ureteral Stent. Nursing Practice \& Research, 13, 77-78.

[19] Zhou, X.J., Xu, H. and Jiang, H.W. (2017) Research Status and Clinical Prospect of Degradable Ureteral Stents. Journal of Clinical Urology, 32, 979-984.

[20] Huang, J.H. (1997) Health Education. Fudan University Press, Shanghai. 